Res Publica. Revista de Historia de las Ideas Políticas ISSN: 1576-4184

\title{
Teología política y máquina de guerra. Schmitt y Deleuze, dos ontologías de la fuerza
}

\author{
María García Pérez*
}

Recibido: 11 de enero de 2018 / Aceptado: 15 de junio de 2018

Resumen. Analizamos aquí la noción de guerra expuesta por Carl Schmitt y por Gilles Deleuze así como sus consecuencias en torno a la categoría de resistencia. Con este objetivo haremos notar que ambos autores parten de una ontología de la fuerza de signo, no obstante, absolutamente diverso. Así de un lado, Schmitt sitúa el criterio de lo político bajo el par amigo/enemigo donde la intensidad de tal oposición será lo determinante para garantizar la homogeneidad; de otro, Deleuze con su nomadología compone su concepto de máquina de guerra como instancia mediante la cual se afirma la diferencia.

Palabras clave: soberanía; resistencia; oposición; homogeneidad; diferencia.

\section{[en] Political Theology and War Machine. Schmitt and Deleuze, Two Ontologies of Force}

\begin{abstract}
We analyze here the notion of war exposed by Carl Schmitt and by Gilles Deleuze and its consequences around the category of resistance. To this end we note that both authors start from an ontology sign of strength, however, quite different. On the one hand, Schmitt placed political criteria under par friend / enemy in the intensity of this opposition is the determining factor to ensure homogeneity on the other, Deleuze with his nomadology up his war machine concept of an instance by which states the difference.
\end{abstract}

Keywords: Sovereignty; Resistance; Opposition; Homogeneity; Difference.

Sumario: 1. Introducción. 2. La teología política de Carl Schmitt. 3. Intensidad: Una ontología de la fuerza en Schmitt. 4. Hostis: Imposible derecho de resistencia. 5. Caosmos: ontología de la fuerza en Deleuze. 6. Acontecimiento y sentido. 7. Máquina de guerra: Resistencia de la diferencia. 8. Conclusiones.

Cómo citar: García Pérez, M. (2018). Teología política y máquina de guerra. Schmitt y Deleuze, dos ontologías de la fuerza, en Res publica 21.2, 305-319.

\footnotetext{
* Universidad de Granada themylam@gmail.com
} 


\section{Introducción}

En el presente estudio buscamos analizar dos miradas contrapuestas respecto de la categoría de guerra dentro de la teoría política, de una parte de la mano de Carl Schmitt y, de otra, mediante la exploración de la reflexión de Gilles Deleuze. En ambos, como veremos, se juega el tratamiento de la diferencia y de la resistencia: en el jurista alemán mediante la construcción de su teología política donde la diferencia es observada desde la negación y la oposición por lo que la (o el derecho de) resistencia se vuelve imposible ${ }^{1}$; mientras que, observaremos, en Deleuze y su tematización de su máquina de guerra, la diferencia es Acontecimiento de suyo afirmativo y la resistencia, así, inevitable. Ahora bien, a pesar de esta distancia entre ambos pensadores, trataremos de mostrar que a los dos les recorre una ontología de la fuerza o intensio que nos esforzaremos por desarrollar para encontrar el núcleo último de esta divergencia.

\section{La teología política de Carl Schmitt}

La teología política cuyo principal representante en el siglo XX es Carl Schmitt ha pensando la soberanía ligada ineluctablemente al Uno trascendente ${ }^{2}$ a través de una teoría decisionista que observa al soberano a distancia respecto del ordenamiento jurídico. No en vano Schmitt postulará un vínculo esencial entre lo político y lo teológico que, aun asumiendo la secularización y desteologización operada desde la Ilustración, no renuncia a reconfigurarlo poniendo sobre la palestra la, a su juicio, irrenunciable verdad del mismo ${ }^{3}$. Este Uno encarnado en el Estado, en el hobbesiano

1 No ignoramos la riqueza de las interpretaciones acerca de la obra de Carl Schmitt así como los prolíficos debates que éstas han suscitado (Cf. J.-F. Kervégan, ¿Qué hacemos con Carl Schmitt?, Madrid, Escolar Mayo, 2014). No obstante el análisis que aquí vamos a ofrecer de las tesis del jurista se enmarca en la discusión abierta entre su teología política y la vertiente impolítica surgida recientemente tal y como la ha denominado Roberto Esposito. Se trata, en sus palabras de un intento por hallar una suerte de "tercera vía" que escape a la repraesentatio teológico-política sin ceder, por otro lado, a la despolitización moderna" (R. Esposito, Confines de lo político: nueve pensamientos sobre política, ed. por Patricio Peñalver, trad. Pedro Luis Ladrón de Guevara Mellado, Madrid, Trotta, 1996, p. 33). En efecto, Esposito habría interpretado a Schmitt en nuestra misma línea encontrando en él, y en la teología política en general, la inserción de la negatividad que se postula necesaria para la legitimación de la soberanía, lo cual se explicaría a través del paradigma inmunitario descubierto por el italiano (Cf. R. Esposito, "Teología política" en Inmunitas, protección y negación de la vida, Buenos Aires, Amorrortu 2005, pp. 96-108). Además Esposito habría virado en los últimos tiempos hacia el pensamiento de Gilles Deleuze para oponer a tal paradigma inmunitario que ejercería aquella negatividad sobre la vida, una biopolítica afirmativa. (Cf. M. Antonelli, "La deriva deleuziana de Roberto Esposito" en Revista Pléyade, Julio-Diciembre 2013, pp. 35-56).

2 Así lo ha observado también Alfonso Galindo Hervás al afirmar que en Schmitt "la vinculación de la soberanía con el carácter representativo de una realidad trascendente constituye uno de los pilares de la teología política". (A. Galindo Hervás, La soberanía, de la teología política al comunitarismo impolítico, Murcia, Res Pública, 2003, p. 25).

3 Del mismo modo argumenta José Luis Villacañas Berlanga. Rescatamos algunos fragmentos por la idoneidad de su interpretación: "La apuesta romana más profunda de Schmitt, su idea hegeliana, consistió en defender que Dios no puede abandonar el mundo —ni aun en las peores circunstancias. (...) (N)o es posible pensar el Estado en su integridad sin la soberanía. Mas en verdad, y esta es la creencia constitutiva de la obra de Schmitt, no puede existir soberanía — ni en último extremo, derecho y orden — al margen de una cierta comprensión metafísica. Y más aún, para comprender esta dimensión metafísica del soberano, necesitamos ir aguas arriba hacia la teología. Sin esta doble dimensión, que afecta al orden de las creencias, el soberano no puede operar y 
Leviatán, presupone una comunidad cerrada donde el criterio último de lo político es la diferenciación decisoria entre amigos y enemigos, donde el horizonte ineludible de la guerra y el estado de excepción marcan el punto álgido de esta distinción basada fundamentalmente en la intensidad de una disociación con el Otro. El soberano es aquel capaz de tomar la decisión la cual no encuentra apoyo en la legislación establecida, ni siquiera en la Constitución, y, en consecuencia, se halla a extramuros del ordenamiento jurídico. Él es capaz de excepcionarlo para protegerlo justamente por su condición de exterioridad trascendente. Como veremos, para Schmitt sólo una instancia alejada del mundo puede actuar de katéchon respecto del caos que supone aquél dejado a su suerte, despolitizado. Por lo demás aquí reside la diferencia que nuestro autor postula una y otra vez entre legalidad y legitimidad: la primera, aun siendo necesaria no es suficiente pues no puede encontrar su fundamento en sí misma, de tal modo que ha de tomar asiento, ha de legitimarse, en una instancia superior que se revela en el análisis del caso excepcional cuyo acaecer guarda la naturaleza del milagro teológico. Andar hacia atrás la senda emprendida por la secularización, por la inmanencia jurídica propia del liberalismo, hasta llegar al núcleo teológico de la soberanía para encontrar allí la fuente de su legitimidad, este es el propósito de Schmitt ${ }^{4}$. Basta recordar algunos fragmentos de su obra Teología política como el que sigue:

Todos los conceptos centrales de la moderna teoría del Estado son conceptos teológicos secularizados. Lo cual es cierto no sólo por razón de su evolución histórica, en cuanto fueron transferidos de la teología a la teoría del Estado, convirtiéndose, por ejemplo, el Dios omnipotente en el legislador todopoderoso, sino también por razón de su estructura sistemática, cuyo conocimiento es imprescindible para la consideración sociológica de estos conceptos. El estado de excepción tiene en la jurisprudencia análoga significación que el milagro en la teología. Sólo teniendo conciencia de esa analogía se llega a conocer la evolución de las ideas filosófico-políticas en los últimos siglos ${ }^{5}$.

De otro lado, no podemos ocultar que lo que una y otra vez busca Schmitt es la paz en el seno de las comunidades así entendidas, de las comunidades cuya soberanía está presupuesta en la forma Estado en tanto único garante, dada la secularización, para exorcizar el conflicto. La excepcionalidad del derecho se postula en aras,

cualquiera que pretenda ejercer su función aumentará el conflicto. (...) El estado de excepción en la comunidad política, como el milagro en la naturaleza, nos habla de un soberano o autoridad trascendente al cosmos político o natural. En esta misma medida, supone un orden natural que alberga la posibilidad real de una recaída. En términos políticos, la noción de estado de excepción supone el momento en que la legalidad, existente hasta ahora, sea cual sea, es ineficaz. El milagro, en tanto intervención directa de Dios, resulta necesario para restablecer la teleología del cosmos hacia su salvación, y por eso supone la destrucción del orden inicial. En los momentos de la ineficacia de la legalidad, el estado de excepción se abre a la fuente de ley y reclama la necesidad de una intervención trascendente que renueve el orden jurídico. En los momentos de la naturaleza caída, la encarnación de Dios en el mundo nos asegura, como milagro arquetípico, la renovación de la potencia del cosmos para caminar a su fin y transfigurarse. De la misma manera, en el momento de un caos que impide el derecho, la eficacia temporal del soberano asegura, con su acción decisoria, la producción de orden suficiente para asegurar la paz y aplicar el derecho" (J. L. Villacañas, Poder y conflicto, ensayos sobre Carl Schmitt, Madrid, Biblioteca Nueva, 2008, pp. 24ss, 114ss).

4 Cf. Ibidem, pp. 112-121.

5 C. Schmitt, Teología política, Madrid, Trotta, 2009, p. 37. 
pues, a eliminar toda disidencia y toda oposición, se encuentre ésta dentro de la propia comunidad o fuera de ella: se trata de la conjuración del caos, de la beligerancia inexorable e inexhaurible de la naturaleza del ser humano o, de otro modo, de la salvación respecto del pecado original ${ }^{6}$.

(N)o hay subordinación ni jerarquía, no hay legitimidad ni legalidad racionales fuera del nexo de protección y obediencia. El protego ergo obligo es el cogito ergo sum del Estado, y una teoría del Estado que sostenga una ignorancia sistemática de este principio será siempre insuficiente y fragmentaria ${ }^{7}$.

Con ello, lo que gesta la soberanía schmittiana es una comunidad homogénea. Efectivamente, porque esta forma de entender la soberanía, como ya se ha apuntado, emerge de una dicotomía, esto es, de una cierta lógica oposicional en torno a las nociones de amigo (Feind) y enemigo (Freund). Pero hay más porque, a nuestro modo de ver, la decisión soberana en Schmitt guarda el secreto de una intensidad (Intensität), y, así, de una ontología de la fuerza aquí atravesada de negatividad según la cual el enemigo emerge como alteridad, como elemento heterogéneo constituyéndose en tanto negación óntica del modo de existencia del amigo, del que cumple con la homogeneidad, con la norma, y que lo enfrenta hasta la muerte. Esto ocurre además tanto a nivel interno como externo: por un lado, hacia el exterior, la decisión soberana apunta al horizonte de posibilidad de guerra entre Estados soberanos; por otro, hacia el interior, esta misma decisión constituye la oportunidad de la guerra civil. Se vislumbra aquí que esta lógica de la negatividad se hace deudora del hegelianismo, de una dialéctica en que la antítesis, el contrario a través de la negación, se convierte en necesario para la definición y el despliegue de la soberanía misma ${ }^{8}$. Pero, también, como decimos, una ontología de la fuerza de la que, en último término, depende el sentido de lo político llevado a su presencia, el sentido del amigo mediante el emerger intensivo del enemigo, de la normalidad a través de la excepción, en suma, de la comunidad política misma.

En lo que sigue, vamos a analizar la argumentación schmittiana deteniéndonos en cada una de estas ideas y extrayendo las consecuencias básicas que luego nos permitan avanzar hacia su discusión de la mano de Gilles Deleuze y su concepto de máquina de guerra.

\section{Intensidad: Una ontología de la fuerza en Schmitt}

Schmitt asegura que toda vez que una contienda, sea en un ámbito cualquiera (religioso, cultural, económico, étnico etc.), llega al punto extremo de identificación del enemigo, nos movemos en el terreno de lo político. Por tanto, la decisión política

6 Schmitt advierte también, al igual que ocurría con el milagro y el estado de excepción, acerca de la cercanía entre la noción teológica de pecado y la concepción de una antropología pesimista respecto de la naturaleza humana como presupuesto necesario para una verdadera teoría política. Cf. C. Schmitt, El concepto de lo político, Madrid, Alianza, 2014, p. 94.

Ibidem, p. 82.

Así lo apunta Alfonso Galindo Hervás cuando afirma que "hacer del enemigo el criterio de lo político no es una opción que tenga por contraria la del elegir al 'amigo', sino una metodológica «negatividad oposicional», necesaria para la definición” (A. Galindo Hervás, op. cit., p. 47). 
carece de contenido a priori, de ahí que Schmitt hable de intensidad: si el criterio en el ámbito estético es el de lo bello y lo feo, si en el ámbito de la moral es el del bien y el mal y si en el ámbito de lo económico es el de rentable y no rentable etc., en el ámbito político de lo que se trata es de que el antagonismo, sea del signo que sea, llegue al punto extremo de la negación óntica del propio modo de existencia.

La distinción política específica, aquella a la que pueden reconducirse todas las acciones y motivos políticos, es la distinción de amigo y enemigo (...) El sentido de la distinción amigo-enemigo es marcar el grado máximo de intensidad de una unión o separación, de una asociación o disociación. (...) El enemigo político no necesita ser moralmente malo, ni estéticamente feo; no hace falta que se erija en competidor económico, e incluso puede tener sus ventajas hacer negocios con él. Simplemente es el otro, el extraño, y para determinar su esencia basta con que sea existencialmente distinto y extraño en un sentido particularmente intensivo ${ }^{9}$ (...) representa en el conflicto concreto y actual la negación del propio modo de existencia (...) No estamos tratando de ficciones ni de normatividades sino de la realidad óntica de la posibilidad real de esta distinción ${ }^{10}$.

De este modo Schmitt, mediante el uso de una estructura formal, logra dotar de autonomía a lo político al mismo tiempo que mantiene el carácter incondicional e irrepresentable de la decisión soberana. Se conforma pues un sujeto soberano que, para serlo, ha de ser necesariamente portador del ius belli. Es así que no sólo decide sobre la muerte del otro sino que, también, dispone de la vida de los miembros del propio pueblo prestos a entrar en lucha. En paralelo, mientras este soberano se inhiba de aplicar aquel derecho de guerra, otorga la vida, bien a otros pueblos soberanos, bien a los individuos del propio pueblo. Ahora bien, creemos que bajo estas premisas podemos entresacar una concepción ontológica en Schmitt que aún no ha sido suficientemente explorada y que tiene que ver específicamente con el uso de la noción de intensidad en el alemán. Apelar a ella, a nuestro juicio, supone en este contexto teórico asumir una ontología de la fuerza que, sin embargo y como veremos, dista mucho de una ontología de la fuerza pensada desde la diferencia y de la que nos ocuparemos más adelante cuando hablemos de Gilles Deleuze. En efecto, la fuerza o intensidad en Schmitt es utilizada para construir una lógica oposicional que distingue contrarios. Es una fuerza, una potencia o intensio, que pertenece al Estado en cuanto efectuación del ser de lo político, y que, en tanto que tal, busca perseverar en su ser. Spinoza y Hegel, el segundo reconocido en su virtud explícitamente por Schmitt, el primero denostado por él y, sin embargo, presente subrepticiamente en sus tesis ${ }^{11}$. La

La cursiva es nuestra.

10 C. Schmitt, El concepto de lo politico, op. cit., pp. 59-61.

11 No hemos encontrado una reconstrucción sistemática de este posible vínculo entre la metafísica de Spinoza y el concepto de intensidad en Carl Schmitt a pesar de los múltiples estudios que hablan de la relación entre ambos pensadores. Pero, aun sin profundizar en la cuestión, alude a ella José Luis Villacañas: “Así que la política antes de la política debe transformar un conflicto social existente en constituyente. Esta transformación - que no es una desnuda construcción o creatio ex nihilo- tiene un nombre en la doctrina de Schmitt: intensificación. Tal concepto tiene una larga historia en la ontología moderna, desde Spinoza, pero aquí no podemos exponerla" (J. L. Villaañas, op.cit., p. 169). También Toni Negri: "El fascismo es esta perversa concepción del poder constituyente, empujado fuera de toda vitalidad, considerado como la negatividad de toda cupiditas. y con esto mismo, en esta perspectiva, arrancado a toda posibilidad de alternativa espacial o temporal a la torna o al destino de lo moderno. La adhesión del pensamiento de Carl Schmitt a la filosofía spinoziana de la potencia está todo situado 
fuerza allí se convierte, por tanto, en motor de negatividad, en aspiración de dominio y en anulación de la alteridad, de la diferencia, en aras de la autoconservación identitaria, de la definición del amigo, de la comunidad. Tanto es así que para Schmitt el Estado no puede disolverse en ningún momento, sino que pervive incluso en el momento excepcional y constituyente decidiéndolo y siendo con ello el garante de lo normal constituido. Para lo político, pues, no existe afuera respecto de la fuerza intensiva que genera oposición. La comunidad política se constituye en Schmitt a condición de esta posibilidad que se cifra en el incremento de la intensidad que llega al extremo de observar la alteridad, la diferencia, como un opuesto, esto es, que sólo sabe afirmarse negando.

Pero hay más, porque aquel formalismo al que aludíamos nos pone sobre aviso de otra cuestión: en Schmitt el sentido es segundo respecto de la fuerza. Que la comunidad sea fenómeno de sentido comprensible, que se articule en torno a un contenido inteligible, sea de la índole que sea, sólo es posible si en primer lugar la fuerza guarda su punto culminante, si la negación intensiva cumple su misión latente. Sólo entonces el sentido llega a presencia, sólo entonces impregna a la comunidad como tal comunidad política. Y otro tanto ocurre en lo que se refiere al ordenamiento jurídico del momento constituido, pues él sólo recibe su legitimación y su fundamento de la fuerza, de la intensidad en la posibilidad de su apoteosis. Desde esta perspectiva, reducir lo político al imperio de la ley, al ordenamiento jurídico sostenido de manera inmanente, tal y como quiso Kelsen con el que Schmitt mantuvo una ardua polémica en sus obras, o a cualquier consideración ética o económica, como es propio del liberalismo, implica olvidar su esencia ontológica, una esencia que es pura intensidad, pura fuerza desplegada para y en el horizonte del conflicto. Una esencia más que nunca olvidada en el siglo XX, caracterizado por Schmitt como la era de la técnica.

En efecto, la técnica, última fase del proceso secularizador que busca la neutralidad, ha sido la vuelta de tuerca final para desfondar el ser de lo político, para restarle intensidad y reducirlo así a cero. Pero la técnica no puede mantener esta situación porque justamente su carácter neutral la revela en tanto útil, esto es, presta para la emergencia de nuevos soberanos, para el repunte de la intensificación de la fuerza y su lógica oposicional y para que, con ello, el sentido de lo político torne a presencia plena.

(T)oda política fuerte habrá de servirse de ella. Por eso concebir nuestro siglo en sentido espiritual como la era de la técnica no puede tener más que un sentido provisional. El sentido definitivo se hará patente cuando quede claro qué clase de política adquiere suficiente fuerza como para apoderarse de la nueva técnica, y cuáles son las verdaderas agrupaciones de amigo y enemigo que prenden sobre este nuevo suelo ${ }^{12}$.

Por tanto, el proceso secularizador reclama siempre, inexorable, una teología política. Es así como definía Schmitt el momento convulso en que le había tocado vivir, ese siglo XX de entreguerras y de rearme que sirvió de antesala a una Segunda Gue-

bajo esta luz. Allí donde la anomalía no logra pasar a ser hegemonía, la alternativa a la utopía es reducida al acto brutal del uso de la fuerza: este es el fundamento cínico del destrozo fascista del poder constituyente". (A. Negri, El poder constituyente, Madrid, Traficantes de sueños, 2015, p. 402).

12 C. Schmitt, El concepto de lo político, op. cit., p. 126. 
rra Mundial. Siguiendo con nuestra interpretación por tanto, tal y como apuntábamos arriba, los procesos neutralizadores pueden entenderse como una suerte de orfandad del sentido respecto de la fuerza. Buscar espacios de sentido tratando de prescindir del conflicto, ínsito en la naturaleza misma del ser humano pero también ontológicamente definitorio del ser de lo político, es simplemente una tarea imposible. El grado máximo de intensidad es, como hemos dicho, posibilidad real (reale Möglichkeit), horizonte ineludible con el que simultáneamente emerge la decisión.

\section{Hostis: Imposible derecho de resistencia}

Como se ha señalado hay dos tipos de enemigos posibles para Schmitt, uno interno, desbaratador del orden y la homogeneidad social dentro del seno de la propia comunidad política, del propio Estado, y otro externo, es decir, un Estado soberano otro que amenaza la soberanía del primero en el orden internacional. Vamos a adentrarnos ahora en la parcela del enemigo interno dado el interés de nuestro estudio.

Pues bien, este enemigo interno tiene un estatuto similar al de, en caso de guerra internacional, el otro Estado soberano en contienda. Se trata, pues, de un enemigo público y sobre él recae la excepción del derecho. Sin embargo no estamos aquí ante la lucha entre dos leviatanes, es decir, entre dos Estados constituidos, sino, como decimos, de un Leviatán frente a su Behemoth decidido. Es importante entender, por tanto, la distinción entre hostis e inimicus que sostiene Schmitt ya que el segundo entra sólo en el orden de lo privado, esto es, con él no se ha alcanzado el grado de intensidad disociativa necesaria para entrar en la órbita de lo político.

Enemigo es sólo un conjunto de hombres que siquiera eventualmente, esto es, de acuerdo con una posibilidad real, se opone combativamente a otro conjunto análogo. Sólo es enemigo el enemigo público, pues todo cuanto hace referencia a un conjunto tal de personas, o en términos más precisos a un pueblo entero, adquiere eo ipso carácter público. Enemigo es en suma hostis, no inimicus en sentido amplio, es es $\pi \mathrm{o} \lambda \dot{\varepsilon} \mu 10 \varsigma$, no $\dot{\varepsilon} \chi \theta \cos ^{13}{ }^{13}$.

Por tanto, inimicus es enemigo en la dimensión privada donde, advierte el jurista, caben las connotaciones psicológicas o sentimentales en torno a un posible odio hacia éste y, también, las cuestiones morales e incluso las económicas. En definitiva, la definición del hostis sigue la misma línea schmittiana que trata de acotar y dar autonomía al concepto de lo político diferenciándolo y haciéndolo específico respecto de otras dimensiones humanas. Así sucede que la guerra, en este caso la guerra civil, es siempre injustificable, no atiende a razones de contenido: ella sólo tiene sentido en el plano del ser, en la dimensión pública como intensio máxima que llega a la disociación oposicional. No caben los argumentos éticos, pues éstos responden a otro criterio que no es el de amigo/enemigo, ni el recurso a la norma jurídica pues ella queda excepcionada, dado que su objetivo es aplicarse a la normalidad cuando ahora lo que impera es la anomia. Hostis es entonces la personificación de la oposición que niega la propia existencia del Estado desde dentro de la unidad política poniéndola así en riesgo. Él

$13 \quad$ Ibidem, p. 61. 
es la diferencia, el que escapa a derecho según la decisión soberana. Además sucede que, según la cita que acabamos de traer, es este nivel de intensidad como presupuesto necesario que alberga a la oposición negadora lo que constituye a un pueblo en sentido político, lo que dota de carácter público a un conjunto de hombres, los amigos, es decir, de soberanía, de poder constituyente garante de lo constituido. El pueblo, identificado con la figura estatal, es unidad que sólo se desgarra, pero también simultáneamente se autodefine, cuando en su seno existe aquella posibilidad real de que emerja el enemigo interno, el Behemoth que quiere la carne del Leviatán.

(E)l Estado es para Hobbes evitación permanente de la guerra civil gracias a un poder gigantesco. De ahí que uno de los dos monstruos, el Leviatán, "el Estado", sojuzgue siempre al otro, el "Behemoth", la Revolución (...). El absolutismo estatal es, por consiguiente, sojuzgador del caos indomeñable que alienta en su misma médula, es decir, en los individuos ${ }^{14}$.

Sí, de continuo hay que volver a la lectura de Schmitt sobre Hobbes, porque lo que de fondo está aquí en cuestión es el derecho de resistencia hecho imposible. La congruencia schmittiana, su rigor lógico, le lleva a eliminar este derecho, porque, recordemos, de lo que se trata aquí es de excepción. Por tanto, la paradoja del Behemoth, del monstruo que enfrenta al Leviatán, es que carece de entidad al margen del propio Estado. Pero, paradójicamente, su relación con él no es otra que la de la decisión soberana sobre su expulsión de la norma jurídica ${ }^{15}$. El Behemoth es una pura negatividad:

(E)n el Estado absoluto de Hobbes, poner el derecho de resistencia como 'tal derecho' en el mismo plano que el derecho estatal, es absolutamente absurdo desde el punto de vista de los hechos y desde el punto de vista del derecho (...). Si se admitiera este derecho dentro del Estado de Hobbes, sería tanto como admitir un derecho a la guerra civil reconocido por el Estado, es decir, un derecho a destruir el Estado; por consiguiente, un absurdo. El Estado pone término a la guerra civil. Lo que no pone término a la guerra civil no es un Estado. Lo uno excluye lo otro ${ }^{16}$.

Vemos pues que la cuestión de la identificación del hostis es correlativa a la negativa de Schmitt de incluir el derecho de resistencia en el orden constituido. El derecho de resistencia recogido en el ordenamiento jurídico, en la legalidad, a ojos de nuestro autor no podría más que entrar en contradicción con la legitimidad que ordena la homogeneidad de la comunidad política y su construcción identitaria irresistible. En efecto, la soberanía en términos de representación, es decir, como Estado, lleva aquí aneja el principio de identidad: el representante soberano lo es de una identidad, la identidad de un pueblo que, para serlo, queda homogeneizado, sujeto a la norma, pacificado ${ }^{17}$.

14 C. Schmitt, El Leviathan en la teoría del Estado de Thomas Hobbes, Buenos Aires, Struhart \& Cía, 1990, p. 21.

15 Desde luego nadie como Giorgio Agamben ha sabido recoger tal situación paradójica por la cual, según las tesis de este autor, la excepción consistiría en una exclusión inclusiva de la vida salvaje (zoé) en el derecho configurando así una relación de bando de esta misma vida respecto de la soberanía. (Cf. G. Agamben, Homo sacer, el poder soberano y la nuda vida I, Valencia, Pre-Textos, 1998).

16 Ibidem, pp. 45-46.

17 Así lo ha visto también Alfonso Galindo Hervás al afirmar que "en Schmitt, no hay identidad sin representación 


\section{Caosmos: ontología de la fuerza en Deleuze}

Si esta interpretación que hemos llevado a cabo es adecuada nos parece de resaltar que Deleuze, en su tratamiento del concepto de máquina de guerra, no traiga en ningún momento a colación a Carl Schmitt que, como hemos visto, es uno de los teóricos más importantes en torno a la noción de guerra y sus vínculos, para él inexorables, con el aparato estatal y su pretendida soberanía ${ }^{18}$. Pero también por esta cuestión que hemos intentado hacer visible en torno a la ontología de la fuerza. Y es que creemos que Deleuze podría darle la razón en un punto a Schmitt, aunque, por supuesto, con matices que hacen que un abismo separe sus concepciones. Porque si bien hemos señalado la existencia de una ontología de la fuerza en el de Plettenberg que hace del sentido, de su venida a presencia en tanto comunidad política como comunidad de los amigos, una cuestión secundaria, derivada, un efecto de la intensidad llevada al extremo y desplegada como oposición identificadora y decisoria del enemigo, en cambio en Gilles Deleuze la ontología de la fuerza, lejos de estar al servicio de la negación y de la oposición y de asentarse en la trascendencia, lo estará al de la afirmación de la multiplicidad creadora e inmanente. Esta ontología en el francés es harto compleja y no es éste el lugar para desplegarla al completo. Basta señalar algunos aspectos clave $^{19}$ :

De un lado, sabemos que para Deleuze la realidad fenoménica esconde otra realidad originante poblada de una pluralidad de fuerzas en continua interacción productiva generadora de aquellos mismos fenómenos. Se trata de una realidad subrepresentativa en la que (des)gobierna la diferencia. En efecto, Deleuze advierte que "el ser de la fuerza es el plural" ${ }^{20}$, es decir, que no existen fuerzas aisladas, al contrario, porque ellas siempre se encuentran en una relación interafectiva en que su potencia singular afecta y es afectada sin cese conformándose como pluralidad irreductible. Cada fenómeno, al que desde esta perspectiva intensiva Deleuze denomina serie, es así un compuesto de fuerzas en movimiento, una ebullición que sólo desde la dimensión del pensamiento representativo queda detenida en la forma de la "cosa", en un objeto para un sujeto. Con todo, la fórmula lógica que Deleuze encuentra para expresar esta relación de pluralidad y de diferencia es la de la sintesis disyunta (y, y, y...) en tanto que unión diferencial de singularidades productora, a su vez, de nuevas diferencias.

(Estado), pero tampoco hay representación sin identidad (el pueblo -la homogeneidad (...). El pueblo, pura potencia amorfa, es incapaz de representar(se) su propia unidad y voluntad. Esto, en el fondo, depende en exclusiva del soberano, que representa y concreta esa problemática homogeneidad" (A. Galindo Hervás, op.cit., p. 38).

18 Referimos aquí bibliografía específica en que ya se ha tratado el nexo entre Deleuze y Schmitt: G. Rae , "Violence, Territorialization and Signification: The Political from Carl Schmitt and Gilles Deleuze", en Theoria and Praxis, Vol. 1, Issue 1, 2013; D. W. Smith, "Flow, Code, and Stock: A Note on Deleuze's Political Philosophy", en Essays on Deleuze, Edinburgh University Press, Edinburgh, 2012, p. 160-172; B. Dillet, The outside of political : Schmitt, Deleuze, Foucault, Descola and the problem of travel, University of Kent, Canterbury, 2012. No obstante lo específico de nuestro estudio se encuentra en la identificación de una ontología intensiva y oposicional en Schmitt comparada con la ontología, también intensiva, de Deleuze pero puesta al servicio de la afirmación de la diferencia.

19 Para esta sección seguimos sobre todo el estudio de L., Sáez Rueda, "Ser, nada y diferencia. El nihilismo nómada de G. Deleuze, más allá de Nietzsche y Heidegger”, en Sáez Rueda/De la Higuera (eds.), Pensar la nada. Ensayos sobre filosofia y nihilismo, Madrid, Biblioteca Nueva, 2007, 418-456.

20 G. Deleuze, Nietzsche y la filosofia, Barcelona, Anagrama, 1971, p. 14. 
(N)os referimos (...) a una operación según la cual dos cosas o dos determinaciones son afirmadas por su diferencia, es decir, no son objetos de afirmación simultánea sino en la medida en que su diferencia es también afirmada, es también afirmativa. No se trata en absoluto de una identidad de los contrarios, todavía inseparable en tanto que tal de un movimiento negativo y de la exclusión. Se trata de una distancia positiva de los diferentes: no ya identificar dos contrarios a lo mismo, sino afirmar su distancia como aquello que los remite uno a otro en tanto que "diferentes"21.

Síntesis disyunta o unión de lo diferente que, sin embargo, conserva (su) la diferencia afirmándola además como creador último de nuevas pujanzas diferenciales. Un movimiento generativo que se cifra pues como autopoiesis inmanente y caosmótica. Es así que, cuando una serie entra en contacto con otra, se produce una suerte de movimiento diferencial, de "movimiento forzado" o "historia embrollada" productora, una vez más, de nuevas diferencias y en la que no rige ningún principio trascendente o teleológico orientador. La ley de este movimiento es, en efecto, inmanente al propio encuentro entre las series, de manera que la diferencia aquí no se deja subsumir por ninguna identidad previa pues ella misma se convierte en nexo. Entra aquí en juego la idea del diferenciante denominado también por Deleuze precursor oscuro o, asimismo, instancia paradójica y que no es otra cosa que la diferencia misma entre las series, una diferencia dinámica, generada en el encuentro entre aquellas pero, también, generadora de nuevas diferencias. Así, ella recorre las series en movimiento sin descanso y procura la emergencia de nuevas intensidades diferenciales:

(E)s preciso que la diferencia relacione de inmediato entre sí los términos que difieren. Es necesario, de acuerdo con la intuición ontológica de Heidegger, que la diferencia sea en sí misma articulación y vínculo, que relacione lo diferente con lo diferente, sin ninguna mediación por lo idéntico o lo semejante, lo análogo o lo opuesto ${ }^{22}$.

Heidegger y Nietzsche son así en Deleuze dos pensadores fundamentales ${ }^{23}$ con los que el francés acomete su particular Destruktion de la metafísica tradicional o, si se quiere, su peculiar inversión del platonismo: "Estos sistemas diferenciales de series dispares y resonantes, con precursor oscuro y movimiento forzado, se llaman simulacros o fantasmas"24. Así es, Deleuze afirma lo que Platón estigmatizó inaugurando la filosofía occidental: los simulacros que no guardaban ninguna semejanza con algún original del que ser copia, aquellos que están en perpetuo movimiento y que son pura diferencia pensada sólo desde sí. De este modo se rebasa también la vieja dicotomía propuesta tradicionalmente por la filosofía que ofrece la elección excluyente entre lo inaprehensible por ser pura multiplicidad que no se pliega a la Identidad, el caos a conjurar, y lo que es ordenado según el concepto, esto es, dentro de los límites de la razón, de la representación, de un Yo bien constituido:

21 G. Deleuze, Lógica del sentido, Barcelona, Paidós, 2005, p. 207.

22 G. Deleuze, Diferencia y repetición, Buenos Aires, Amorrortu, 2002, p. 183.

23 Tal y como señala Luis Sáez Rueda, lo que tenemos en Deleuze respecto de Heidegger es una superación y profundización de su tratamiento de la diferencia a través de Nietzsche de manera que el ser heideggeriano es ahora el que queda atravesado y constituido por las fuerzas nietzscheanas. (Cf. L. Sáez Rueda, op.cit., pp. 418-456).

24 G. Deleuze, Diferencia y repetición, op.cit., p. 196. 
Lo que es común a la metafísica y a la filosofía trascendental es, en primer lugar, esta alternativa que nos imponen: o bien un fondo indiferenciado, sin-fondo, noser informe, abismo sin diferencias y sin propiedades; o bien un Ser soberanamente individuado, una Forma fuertemente personalizada. Fuera de ese Ser y de esa Forma, no queda sino el $\operatorname{caos}^{25}$.

Este rebasamiento, como estamos tratando de explicar, consiste en concebir el ser de lo real como multiplicidades de síntesis disyuntas, al cabo, pues, como esa multiplicidad móvil fraguada por la intensio que, sin embargo, se ordena de forma inmanente en el encuentro mismo entre las fuerzas, entre las series, y cuyo engarce es la diferencia misma. Inversión del platonismo que da voz y derecho de existencia a los simulacros: "el enemigo gruñe, insinuado por doquier en el cosmos platónico, la diferencia se resiste a su yugo, Heráclito y los sofistas arman un estrépito infernal"26. Deleuze traduce este gruñido para la filosofía y, tal y como hizo Nietzsche, rescata a Heráclito.

\section{Acontecimiento y sentido}

A esto se añade que para nuestro autor el sentido es efecto, derivado secundario producido en el encuentro entre los fenómenos-serie y la consciencia-serie, esto es, él se genera en el mundo caosmótico e intesivo, pre-subjetivo y pre-fenoménico, en que se pergeña la extensio, los objetos y los sujetos tal cual se dan a la representación. Es frontera y articulación entre el sujeto que designa y los estados de cosas designados sin confundirse con ellos, porque a ambos hay que entenderlos como conjunto de singularidades en movimiento distribuidas por el diferenciante, esto es, como series intensivas. El sentido es, pues, un efecto de posición del diferenciante mismo y, en tanto que tal, supone la subida a la superficie extensa de aquella multiplicidad móvil que actúa en profundidad. En esta dimensión fenoménica y representativa se crea la ilusión de parálisis de la agitación de las fuerzas. Pero el sentido no es más que el producto de las distribuciones diferenciales y sin cese de las relaciones intensivas y, por tanto, esconde, paradójicamente, hondas relaciones con el sinsentido, con una profundidad de singularidades en relación de intensión que per se son asignificativas. "El sentido no es nunca principio ni origen, es producto. No está por descubrir, ni restaurar ni reemplazar, está por producir con nuevas maquinarias. No pertenece a ninguna altura, ni está en ninguna profundidad, sino que es efecto de superficie"27. El sentido es, pues, Acontecimiento ${ }^{28}$ que se desdobla en dos caras, una subrepresentativa, o, en palabras de Deleuze, contrafáctica, y otra representativa o fáctica. Aquí es donde verdaderamente Deleuze opera su particular inversión del platonismo $y$, por ende, de toda la filosofía Occidental que ha visto en el sentido una suerte de maná por el que el mundo y sus estados de cosas se nos develaban. No, el sentido

\footnotetext{
G. Deleuze, Lógica del sentido, op.cit., p. 139.

G. Deleuze, Diferencia y repetición, op.cit., p.197.

G. Deleuze, Lógica del sentido, op. cit., p. 103.

Françoise Zourabichvili ha calificado la obra de Deleuze como una filosofía del acontecimiento remarcando así la importancia de este concepto dentro del pensamiento de nuestro autor (Cf. F. Zourabichvili, Deleuze. Una filosofía del Acontecimiento, Buenos Aires, Amorrortu, 2011).
} 
viene después, lo primero es esta realidad sub-representativa, fuera del concepto: nihil productivo. En consecuencia también son segundos los productos de la lógica de la representación, que para nuestro autor son fundamentalmente la identidad, la oposición, la analogía y la semejanza:

(D)ecíamos que la representación se definía por ciertos elementos: la identidad en el concepto, la oposición en la determinación del concepto, la analogía en el juicio, la semejanza en el objeto. (...) El Yo [Je] pienso es el principio más general de la representación, es decir, la fuente de esos elementos y la unidad de todas esas facultades: yo concibo, yo juzgo, yo imagino, yo me acuerdo, yo percibo; como los cuatro brazos del Cogito. Y, precisamente, sobre esos brazos se crucifica la diferencia. Cuádruple grillete donde sólo puede ser pensado como diferente lo que es idéntico, parecido análogo y opuesto ${ }^{29}$.

Con todo, donde nosotros vamos a poner el acento a partir de ahora es en la cuestión de la oposición dada la dicotomía amigo/enemigo traída por Schmitt y que hemos tratado en anteriores apartados. Sin adentrarnos más en la complejidad deleuzeana, los elementos que hemos expuesto de su ontología nos son suficientes para dar cuenta de su noción de máquina de guerra. Este concepto, como veremos, se encuentra en el contexto del paso deleuzeano hacia una teorización socio-política, justo ahí donde la ontología se transforma explícitamente en nomadología y donde vamos a señalar las diferencias respecto de Carl Schmitt y su teología política.

\section{Máquina de guerra: Resistencia de la diferencia}

En primer lugar debemos entender aquí que las fuerzas a las que hemos aludido en esta ontología ahora, en el ámbito socio-político, toman la forma del deseo. El deseo pertenece así a la región pre-subjetiva, esto es, inconsciente. Un inconsciente o Ello que Deleuze concibe como máquina por su actividad productora de más y más deseo. En efecto, la fuerza que deshilacha al yo hasta pulverizarlo en una multiplicidad intensiva es descrita ahora por el de París como deseo, al tiempo que el Ello se concibe como fábrica o máquina que lo produce sin cesar. Deseo plural, múltiple, en y por la diferencia, que no se vincula a un objeto constituido sino a su envés constituyente, subrepresentativo y bullicioso. Un deseo que es en este sentido rizomático, nómada y afirmativo y que sólo la representación, la constitución del fenómeno aprehendido ya por la conciencia, hace que se detenga, se sedentarice, y pase a ser un deseo codificado, un deseo al que se le imprimen límites y cauces, un deseo, en fin, socialmente estriado, cualificado, significado, dirigido a objetos concretos. Sólo en este punto emergen la negación y la oposición, las dicotomías excluyentes. Pero al nomadismo maquínico deleuzeano no le pertenece en absoluto la lógica binaria, menos aún la de la oposición. Lo que constituye de fondo la realidad fenoménica pero también lo político social es la diferencia misma que, en tanto que tal, resiste. En efecto, en el sistema deleuzeano la diferencia no puede ser absolutamente neutralizada porque ella es natura naturans ${ }^{30}$, intensio plural que (des)organiza lo real constituido al tiempo que lo gesta. La diferencia, pues, el deseo

G. Deleuze, Diferencia y repetición, op.cit., p. 213.

30 Esta terminología spinoziana es la que destaca y utiliza el profesor Luis Sáez Rueda para explicar la diferencia e 
pre-codificado, es condición de posibilidad de toda codificación y, a la vez, de la emergencia de novedad, de más diferencia. En él reside toda fuerza transformadora de la realidad constituida, de toda institución y, como vamos a ver, de todo Estado.

Ahora bien, esta máquina deseante que somos en profundidad, este pueblo en sentido diferencial y rizomático, como decimos, es, a su vez, la otra cara del pueblo homogeneizado, constituido, mediado institucionalmente, representado. En efecto, si como dijimos antes tanto el sujeto como cualquier fenómeno podía observarse bien desde su faz anclada en la representación o bien desde su faz subrepresentativa en tanto "serie", del mismo modo sucede con la categoría de pueblo. Pueblo en este segundo sentido aludiría pues a un constituyente perenne que siempre resiste al agostamiento que supone su rostro constituido el cual crea la fantasmagoría de una detención del insistente movimiento que se agita bajo él. Y es ahí donde la máquina deseante y nomádica que somos puede ser adjetivada con el complemento del nombre guerra, esto es, donde surge toda oposición:

En la medida en que la guerra (con o sin batalla) se propone el aniquilamiento o la capitulación de fuerzas enemigas, la máquina de guerra no tiene necesariamente por objeto la guerra (...) El problema de la guerra queda, pues, a su vez relegado y subordinado a las relaciones máquina de guerra-aparato de Estado ${ }^{31}$.

¿Cuál es la naturaleza de esta relación? ¿Cómo deviene la guerra predicado de la máquina si no es intrínseca a ella en su origen? Nos adentramos en la cuestión estatal porque para Deleuze la máquina de guerra es inseparable de ella. Pues bien, para el pensador francés, el Estado es un "Urstaat inmemorial” ${ }^{2}$, esto es, designa los diversos modos en que la intensio-deseo plural y rizomática ha sido efectuada, instituida, a lo largo de la historia. La guerra por su parte designa la relación oposicional por la que emerge el enemigo, esto es, lo otro como un opuesto, y, por tanto, es lo propio de lo constituido, de lo fijado, de lo que tiene límites o está estriado. Pertenece pues al Estado y sólo pertenecerá a la máquina en tanto que puesta en relación con éste. Según tal análisis, en ambos casos a nuestro juicio, la potencia creativa y nomádica de la diferencia languidece en un tipo de efectuación, la efectuación del fenómeno político-estatal, en que la negatividad llega al extremo de la guerra.

(L)a máquina de guerra era la invención nómada, puesto que en su esencia era el elemento constituyente del espacio liso, de la ocupación de ese espacio, del desplazamiento en ese espacio, y de la composición correspondiente de los hombres: ese es su único y verdadero objetivo positivo (nomos). (...) Si la guerra deriva necesariamente de la máquina de guerra es porque ésta se enfrenta a los Estados y a las ciudades, como fuerzas (de estriaje) que se oponen al objeto positivo: como consecuencia, la máquina de guerra tiene como enemigo al Estado, a la ciudad, al fenómeno estatal y urbano, y su objetivo es aniquilarlos. Ahí es donde deviene guerra: aniquilar las fuerzas del Estado, destruir la forma-Estado ${ }^{33}$.

interrelación entre la intensio y la extensio deleuzianas, la primera como natura naturans y la segunda en tanto natura naturata. (Cf. L. Sáez Rueda, El Ocaso de Occidente, Barcelona, Herder, 2015).

31 G. Deleuze, \& F. Guattari, Mil mesetas, capitalismo y esquizofrenia, Valencia, Pre-textos, 2002, pp. 416-417.

32 Ibidem, p. 436.

33 Ibidem, p. 417. 
Sí, a ojos de Deleuze Schmitt tenía razón, pero sólo desde la perspectiva superficial y no genética de la extensio y la representación. No obstante el movimiento intensivo, acodificado, fuente de toda transformación insiste y resiste configurando un Behemoth silente e inagotable. La resistencia es por tanto en Deleuze de hecho, sea o no de derecho. Resistir es crear, hacer emerger nuevas líneas de fuga, nuevas significaciones, nuevos códigos, nuevas instituciones, vale decir, siguiendo la ontología deleuzeana, es afirmar la diferencia, dejar que los simulacros suban a la superficie y trastoquen la representación. Resistir es un constituyente ineludible, una revolución en que los afectos, los deseos, son armas que deshacen los límites puestos al deseo, las codificaciones, en suma que, desterritorializan lo territorializado arrasando con las fronteras en busca de una nueva Tierra.

Cabe hacer una pequeña digresión a esta altura porque en el apartado correspondiente a Schmitt habíamos afirmado que el jurista habría rescatado, paradójicamente dada su aversión al pensador judío, el tema spinoziano de la perseveración en el ser. Toda la estrategia de la soberanía a través del estado de excepción venía encaminada, desde esta perspectiva, a la persistencia del ser de lo político para mantenerse en sus cauces constituidos. Ahora bien, sabemos, por los diversos estudios que le dedica, que Spinoza es un autor fundamental para Deleuze. Tal aseveración spinoziana, dada la ontología que hemos visto hasta aquí, es interpretada por el francés de manera muy distinta al encaje schmittiano. En efecto, Deleuze entiende por tal expresión la tendencia de la fuerza, en Spinoza del conatus, a llegar hasta el límite de lo que ella puede, vale decir, a afirmarse en su diferencia cualitativa hasta el final, esto es, hasta el límite de su poder de afectar y verse afectada, de producir más diferencia. Por tanto, el esfuerzo en la perseverancia en el ser no puede desvincularse, en Deleuze-Spinoza, de los encuentros interafectivos ${ }^{34}$ que, al cabo, en el ámbito intensivo, son el germen de la extensio y sus fenómenos observables. En consecuencia, lo que persevera en su ser aquí es la diferencia misma y su organización caosmótica, la multiplicidad, y no, en absoluto, el Uno en tanto ser homogéneo y homogeneizante. Una multiplicidad de la que depende esa resistencia que estamos tematizando y con la que Deleuze contradiría a Schmitt en el punto fundamental de su argumentación: la soberanía no pertenece al Estado, sino a esta suerte de desobediencia (in)civil e impolítica. En efecto, si seguimos esta reflexión podemos colegir que la soberanía entendida como el elemento constituyente por antonomasia no tiene que ver con la decisión estatal acerca de la excepción del derecho porque ella supone una negación segunda, propia de la lógica oposicional ligada a la representación, a la que precede una afirmación más fundamental que aquella: la afirmación creadora de la diferencia. Es esta como decimos una soberanía impolítica, esto es, una soberanía que de continuo desfonda la soberanía de lo constituido y que nos arroja al ámbito de una insurrección que resiste de toda parte a la homogeneización (siempre violenta) procurando la mutabilidad del mundo político-social desde la inmanencia caosmótica ${ }^{35}$.

34 Cf. G. Deleuze, Spinoza, filosofia práctica, trad. Antonio Escohotado, Buenos Aires, Tusquets, 2004, pp. 27-32.

35 En este sentido argumenta Philippe Mengue cuando trata el concepto de utopía en relación a Deleuze, el cual ya no designaría la esperanza en un futuro soñado en que la revolución viniera a realizarse resolviendo los conflictos de la humanidad de una vez por todas. Mengue, resaltando la herencia nietzcheana de nuestro autor, apela a un concepto de utopía libre de ideales, asentado en la inmanencia e incardinado en el presente del Acontecimiento. (Cf. P. Mengue, Utopies et devenirs deleuziens, Paris, L'Harmattan, 2009). 


\section{Conclusiones}

Podemos decir, a tenor de todo lo anteriormente expuesto y analizado, que el concepto de guerra queda circunscrito, tanto para Schmitt como para Deleuze, al conflicto del que emerge la soberanía de lo políticamente constituido. Ella es la instancia que marca, aun como horizonte, el momento decisivo en que lo instituido acontece como tal a través de la oposición y, por tanto, de la negación. Sin embargo, hemos observado con Deleuze y su ontología de la diferencia intensiva, una posibilidad constituyente plenamente afirmativa. En efecto, el pensamiento de la diferencia deleuziano llevado a su ámbito socio-político, expresa, a través de la categoría de lo molecular, pero también de la de pueblo o la de nomadismo, un tratamiento de la multiplicidad heterogénea que otorga al Behemoth schmittiano una faz distinta a la que el jurista nos ofrece. Aquí es donde se juega, en el fondo, toda la cuestión en torno a la guerra y, por ende, a la soberanía. Entender ésta desde el plano de lo constituido, de un pueblo ya homogeneizado, de un Estado efectuado, de una Constitución escrita y, a su vez, como ocurre en Schmitt, de un afuera en que se asentaría la legitimidad en tanto que sólo busca conservarlos, es restringir la mirada observando la alteridad heteróclita como enemigo potencial. Esta visión no se ha rendido aun hoy en nuestra actual era de globalización y puesta en crisis del modelo de soberanía estatal. Bien supo ver Schmitt que el liberalismo en su vertiente ética, esto es, mediante el concepto de humanidad, no hace más que reinventar al enemigo para llevarlo hors l'humanité. El capitalismo globalizado y neoliberal es, efectivamente, el nuevo aparato de captura del deseo acodificado al que otorga significaciones en aras de la rentabilidad. El enemigo, hoy, es lo no rentable. Pero, si esto es así, no es menos cierto, desde la perspectiva ontológica, que lo que tenemos de fondo es, a su vez, un hors l'être, o, si se quiere, un hors l'être-avec. Porque no es sólo la vida de las personas y sus condiciones materiales las que están en juego, sino el ser mismo. Negar la diferencia es tanto como negar su capacidad creativa, esto es, la posibilidad de atisbar tierra nueva $y$, con ello, de efectuar otros modos de darse o instituir la comunidad humana. 